\title{
EL DERECHO A LA ESTABILIDAD LABORAL DE PERSONAS CON DISCAPACIDAD EN COLOMBIA: LAS MUJERES DESVINCULADAS DEL “FONDO ROTATORIO DE LA POLICÍA NACIONAL”
}

\author{
THE RIGHT TO LABOR STABILITY FOR PEOPLE WITH \\ DISABILITIES IN COLOMBIA:THE FIRED FROM THE \\ "NATIONAL POLICE ROTARY FUND"
}

\author{
José Reynel Cristancho Díaz ${ }^{(1)}$ \\ Universidad del Cauca, Colombia
}

\begin{abstract}
Resumen: En el presente artículo se toma como punto de partida la explicación del principio de estabilidad en el empleo y cómo este se constituye en un derecho fundamental que otorga un fuero reforzado a determinados grupos de especial protección debido a su situación de vulnerabilidad, dentro de los que se encuentran las personas con discapacidad. Analiza el caso de un grupo de mujeres con discapacidad que trabajaban en una entidad del Estado y que perdieron sus empleos de manera simultanea pese a gozar de este fuero. Estudia las acciones de tutela de derechos fundamentales que instauraron algunas de estas trabajadoras con el propósito de que los dispusieran su reintegro laboral. La finalidad del presente artículo es verificar la efectividad de este recurso constitucional, así como la aplicación del precedente constitucional frente a casos de estabilidad laboral reforzada de personas con discapacidad.
\end{abstract}

Palabras clave: persona con discapacidad, acción de tutela, derecho fundamental, estabilidad laboral reforzada, primacía de la realidad.

Abstract: This article explains the principle of stability in employment, and how this constitutes a fundamental right that grants a reinforced jurisdiction to certain special protection groups like people with disabilities. It analyzes the case of a group of disabled women who worked in a State Entity and who lost

(1) Abogado egresado de la Universidad del Cauca. Diplomado en Políticas Públicas para las Víctimas y Construcción de Paz por el Instituto Interamericano de Derechos Humanos en conjunto con la Unidad para la Atención y Reparación Integral a las Víctimas. Tecnólogo en Criminalística y Ciencias Forenses egresado de la Fundación Tecnológica San Francisco de Asís. jcristanchod@gmail.com 
their jobs simultaneously despite enjoying this jurisdiction. Studies the actions of protection of fundamental rights that some of these workers instituted with the purpose of having them reinstate their work. The purpose of this article is to verify the effectiveness of this constitutional remedy, as well as the application of the constitutional precedent against cases of reinforced labor stability of persons with disabilities.

Keywords: person with disability, guardianship action, fundamental right, reinforced job stability, primacy of reality. 


\section{Introducción}

La promulgación de la Constitución Política de 1991 se erige como un hito en la historia jurídica de Colombia, pues en ella se relacionan de manera expresa un gran número de derechos fundamentales ${ }^{(2)} y$, por otro lado, se acepta la existencia de otros derechos que, a pesar de no encontrarse enunciados expresamente en la Carta, pueden ostentar tal categoría en el ordenamiento jurídico interno ${ }^{(3)}$. Uno de los derechos que se encuentra consagrado como fundamental es el del trabajo (artículo 25), el cual contiene una serie de principios que hacen parte de su núcleo esencial y que se encuentran relacionados en el artículo 53 de la Carta.

El derecho al trabajo, como todo derecho fundamental, obliga al Estado a proteger y garantizar su ejercicio; sin embargo, es claro que se pueden presentar casos en los que la integridad de este derecho se ve comprometida debido a las acciones $u$ omisiones del empleador, sea este un particular o una entidad del Estado. Ante esto, la misma Constitución Política cuenta con la acción de tutela como mecanismo de protección inmediata de estas garantías constitucionales a través de un proceso preferente y sumario, cuyo fallo es de inmediato cumplimiento; estas características han llevado a concluir que esta acción "es el mecanismo más importante consagrado por la Constitución de 1991 en materia de defensa de los derechos fundamentales" (Carrera, 2011:94).

Además de la protección de este tipo de derechos, la acción de tutela ha contribuido a que, en el marco de la facultad de revisión, la Corte Constitucional de Colombia haya tenidola oportunidad de interpretar el texto constitucionaly determinar el alcance y contenido de los derechos fundamentales en él incorporados; así, es posible hallar amplia jurisprudencia de este Alto Tribunal que desarrolla el derecho al trabajo y los principios que hacen parte de su núcleo esencial, pronunciamientos en los que se concretan los derechos de los trabajadores y las obligaciones que le asisten tanto a los empleadores como al Estado en su protección y garantía.

Uno de estos derechos es el de la estabilidad laboral reforzada de las personas con discapacidad, frente al cual el Alto tribunal en materia constitucional

(2) El capítulo I del Título II de la Constitución Política señala de manera expresa los derechos considerados como fundamentales.

(3) Existen diversos criterios para identificar derechos que ostentan la categoría de fundamental además del criterio de la taxatividad. Uno de ellos es el de la conexidad, que hace alusión a aquellos derechos que guardan una relación intrínseca con algún derecho de carácter fundamental y que, por tanto, requieren una protección y garantía igual. Otro de estos criterios es el del bloque de constitucionalidad, según el cual todos aquellos derechos que se encuentren consignados en instrumentos internacionales de derechos humanos ratificados por el Estado ingresan al ordenamiento jurídico interno al mismo nivel que la Constitución. Finalmente, se tiene el criterio de los derechos innominados, desarrollado por el artículo 94 de la Carta y que hace alusión a aquellos derechos que, sin estar enunciados textualmente en la Constitución o en un instrumento internacional de derechos humanos ratificado por el Estado, son inherentes a la persona y, por lo tanto, cuentan con protección constitucional. 
ha desarrollado unas reglas y principios a tener en cuenta para determinar si una persona que es titular de este derecho puede ejercer su protección a través de la acción de tutela. En este sentido, el presente artículo estudia la desvinculación masiva de mujeres con discapacidad del Fondo Rotatorio de la Policía Nacional, haciendo especial énfasis en 10 de estas mujeres, pues fueron las únicas que accedieron a compartir la información de sus procesos de vinculación con esta entidad estatal, las patologías que padecían, así como el resultado de las acciones legales de protección inmediata que ejercieron en procura de defender sus derechos.

\section{El derecho al trabajo en Colombia}

La Constitución Política de Colombia entiende el trabajo no solo como un derecho fundamental, sino que también lo concibe como un fin hacia el cual tiende el ordenamiento jurídico al estar descrito dentro del preámbulo de la Carta $y$, en adición, en su primer artículo reconoce que el Estado Social de Derecho se encuentra fundado en el respeto de la dignidad humana, la solidaridad y el trabajo. En este orden, el trabajo tiene una especial relevancia jurídica en atención a la incidencia de este en la consecución de una vida digna para la persona, pues, como bien lo señala Molina (2007. p. 177), el trabajo se constituye en "una vía que permite la autonomía y la autorrealización del individuo, así como la generación de solidaridad social". En cuanto a su carácter de derecho fundamental, el mismo se predica por su consagración expresa en el artículo 25 de la Constitución, pero no se puede dejar de lado que la importancia de este derecho es tal que se encuentra reconocido en diversos tratados internacionales ${ }^{(4)}$, lo que ha incidido a que se le llegue a considerar como un derecho humano (Avendaño, 2014).

\subsection{Los principios mínimos fundamentales del derecho al trabajo}

Estos se encuentran relacionados en el artículo 53 de la Constitución Política de Colombia, principios frente a los que, debido a su naturaleza, Guerrero (1999) ha puntualizado que se erigen como los cimientos de la organización jurídica laboral, pues con estos se fundamenta y define el sentido de las disposiciones del derecho del trabajo. Por su parte, Vásquez (1999. p. 118) considera que estos principios "operan a modo de líneas fundamentales e informadoras que inspiran directamente soluciones que sirven, no ya sólo para la sanción, sino también para la interpretación de la norma y para la resolución de casos concretos". En este orden, se procede a hacer una explicación sucinta de aquellos principios que inciden directamente en el análisis del caso objeto de estudio.

(4) Dentro de los tratados internacionales que reconocen el derecho al trabajo se destacan los siguientes: Declaración Universal de Derechos Humanos (art. 23); Pacto Internacional de Derechos Económicos, Sociales y Culturales (arts. 6 y 7); Protocolo Adicional a la Convención Americana sobre Derechos Humanos en materia de Derechos Económicos, Sociales y Culturales "Protocolo de San Salvador" (art. 6); Convención sobre los Derechos de las Personas con Discapacidad (art. 27). 


\subsubsection{La estabilidad en el empleo}

La Corte Constitucional (1994) considera que este principio se constituye en una garantía con la que cuenta el trabajador para permanecer en su empleo, siendo este una actividad de provecho propio y social; así, la estabilidad en el empleo tiene como finalidad garantizar un medio para el sustento del individuo y contribuir a la trascendencia de este en la sociedad, pues es claro que la persona, además de la remuneración, busca otras satisfacciones de orden personal, como lo son la cooperación, estimación y desarrollo de su personalidad. Aunque eso no quiere decir que este principio sea absoluto, pues dentro de la legislación existen causales que justifican el despido de un trabajador en procura de brindar herramientas jurídicas a los empleadores frente a los trabajadores que incumplan las obligaciones que tienen en el marco de una relación laboral.

Así las cosas, la estabilidad laboral implica que, de no existir una causa que justifique el despido, el trabajador, incluso contra la voluntad del empleador, cuenta con la garantía de permanecer en su empleo y, por lo tanto, obtener los respectivos beneficios salariales y prestacionales (Corte Constitucional, 1997b). En adición, se ha precisado que:

La estabilidad es un verdadero derecho jurídico de resistencia al despido, que demuestra que los fenómenos laborales no se rigen exclusivamente por el principio de la autonomía de la voluntad, pues están involucrados otros valores constitucionales, especialmente la dignidad del trabajador y la búsqueda de una mayor igualdad entre patrono y empleado. (Corte Constitucional, 2003:6)

No obstante lo anterior, se debe precisar que, de acuerdo con la legislación laboral colombiana, los empleadores pueden despedir a sus trabajadores sin que medie una justa causa siempre que efectúen una indemnización en estricto apego a lo descrito por el Código Sustantivo del Trabajo; pero, si bien esta se constituye en la regla general, existen ciertas excepciones en las que, como se explicará más adelante con mayor detenimiento, la estabilidad en el empleo se erige como un derecho fundamental de carácter absoluto, pues le está prohibido al empleador dar por terminada la relación laboral so pena de tener que efectuar el reintegro del trabajador y el pago de una sanción.

\subsubsection{La primacía de la realidad}

Este principio se encuentra relacionado también con el principio de prevalencia del derecho sustancial y busca proteger al trabajador en atención a la posición de superioridad con la que cuenta frente a él el empleador (Corte Constitucional, 2016a) y aplica tanto para las relaciones laborales entre particulares como en aquellas celebradas por el Estado (Corte Constitucional, 2018). En 
concreto, el propósito de este principio es el de determinar la existencia o no de una relación laboral, pues de existir el trabajador gozaría de todas y cada una de las garantías que el ordenamiento jurídico laboral contempla y, por lo tanto, el empleador debe asumir el cumplimiento de las obligaciones que se derivan de estas garantías. Frente a esta temática De la Cueva (1943) explicó que:

La existencia de una relación de trabajo depende, en consecuencia, no de lo que las partes hubiesen pactado, sino de la situación real en que el trabajador se encuentre colocado y es que, como dice Secelle, la aplicación del derecho del trabajo depende cada vez menos de una relación jurídica subjetiva, cuanto de una situación objetiva; cuya existencia es independiente del acto que condiciona su nacimiento. De donde resulta erróneo pretender juzgar la naturaleza de una relación de acuerdo con lo que las partes hubieren pactado, ya que, si las estipulaciones consignadas en el contrato no corresponden a la realidad, carecerán de todo valor. (p. 381)

En este mismo sentido, la Corte Constitucional ha usado el principio de "supremacía de la realidad sobre formalidades establecidas por los sujetos de las relaciones laborales" al momento de analizar acciones de tutela instauradas en procura de que se reconozca la existencia de una verdadera relación laboral con todo lo que ello implica, tanto para el trabajador, como para el empleador; así, se ha puntualizado que no interesan los términos utilizados por las partes contratantes para determinar la naturaleza de la relación que celebran "o de la forma que pretendan dar a la misma, importa, a los ojos del juez y por mandato expreso de la Constitución, el contenido material de dicha relación, sus características y los hechos que en verdad la determinan" (Corte Constitucional, 1997a:10).

\subsection{La estabilidad laboral reforzada como derecho fundamental}

La Corte Constitucional (2017c) ha aclarado que a pesar de que los empleadores tienen la facultad de regular la duración de la relación laboral con sus trabajadores, esta autonomía encuentra una limitante en la obligación de garantizar la permanencia en el empleo a aquellos trabajadores que se encuentren en una circunstancia de debilidad manifiesta, lo cual se traduce en un derecho fundamental para el trabajador, denominado "estabilidad laboral reforzada". Así las cosas, se han identificado como titulares de este derecho fundamental a las mujeres embarazadas, aforados sindicales, madres cabeza de familia y las personas con discapacidad o en condición de debilidad manifiesta por motivos de salud (Corte Constitucional, 2018), frente a quienes el despido se puede materializar únicamente si el empleador cuenta con "una especial autorización de la oficina del trabajo o del juez" (Corte Constitucional, 2008:16). 
Ahora bien, atendiendo a la naturaleza de caso estudiado, es pertinente hacer claridad respecto a que el derecho fundamental en comentario no se predica de manera exclusiva de los contratos de trabajo a término indefinido, sino también a otras modalidades de vinculación laboral, como es el caso de los contratos a término fijo; esto teniendo en cuenta que el vencimiento del plazo pactado no es suficiente para legitimar la decisión de un empleador de no renovar este tipo de contratos o darlos por terminados cuando "(i) subsiste la materia del trabajo, las causas que lo originaron o la necesidad del empleador; (ii) el trabajador ha cumplido efectivamente sus obligaciones contractuales; y (iii) se trate de una persona en una situación de debilidad" (Corte Constitucional, 2015:72).

\subsubsection{Las personas con discapacidad como titulares de estabilidad laboral reforzada}

Como se enunció con antelación, las personas con discapacidad son titulares de este derecho fundamental, el cual se deriva no solamente de la interpretación de la Constitución colombiana, sino que encuentra una mención expresa en el artículo 26 de la Ley 361 de 1997, según el cual "ninguna persona en situación de discapacidad podrá ser despedida o su contrato terminado por razón de su discapacidad, salvo que medie autorización de la oficina de Trabajo", imponiendo, además, como sanción para aquellos empleadores que desconozcan esta prohibición el pago de 180 días de salario al trabajador, así como su reintegro a la labor que se encontraba desempeñando.

Al respecto, la Corte Constitucional (2015) ha expresado que el reconocimiento como derecho fundamental de la estabilidad laboral reforzada de las personas con discapacidad se constituye en una acción afirmativa que el Estado adopta con el propósito de defender a este grupo poblacional aminorando o, en su caso, suprimiendo las desigualdades a nivel cultural, económico, histórico o social que los afectan, buscando con esto que tengan una mayor representación en los aspectos político y/o social. En adición, esta misma Corporación, a través de una sentencia de unificación jurisprudencial, explicó que:

Una persona en condiciones de salud que interfieran en el desempeño regular de sus funciones se encuentra en condiciones de debilidad manifiesta no solo porque esto puede exponerla a perder su vínculo, como lo muestra la experiencia relacionada en la jurisprudencia constitucional, sino además porque le dificulta la consecución de una nueva ocupación con base en sus facultades, talentos y capacidades humanas, que le depare los bienes suficientes para satisfacer sus necesidades básicas, con lo cual está en riesgo no solo su estabilidad y su dignidad, sino incluso su propia subsistencia, y su seguridad social. (Corte Constitucional, 2017a:19) 
Por otro lado, el Alto Tribunal ha dejado claro que al momento de analizar un caso en el que la persona aduce ser titular del derecho a la estabilidad laboral reforzada por tener una discapacidad no es obligatorio que exista una calificación previa de la pérdida de capacidad laboral, esto teniendo en cuenta que la protección que cobija a las personas con discapacidad se predica de todos aquellos individuos que tengan limitaciones físicas o psicológicas sin que interese si el grado de afectación es leve, moderado o severo (Corte Constitucional, 2017b).

El sustento de esta postura no se deriva exclusivamente de postulados constitucionales como los principios del Estado Social de Derecho, la igualdad y la solidaridad social, pues la misma se ha consolidado luego de una armonización entre estos y los tratados internacionales de derechos humanos ratificados por el Estado colombiano (Corte Constitucional, 2017b), siendo el más importante de ellos la Convención sobre los Derechos de las Personas con Discapacidad, cuyo artículo 27 reconoce el derecho de este grupo poblacional "a trabajar, en igualdad de condiciones con las demás... incluso para las personas que adquieran una discapacidad durante el empleo...".

Lo anterior cobra especial relevancia si se tiene en cuenta que, como lo señala Canessa (2012), de manera reciente "asistimos a una revaloración del Derecho Internacional del Trabajo, donde su reposicionamiento se ve fortalecido con los derechos humanos laborales el espacio de intersección entre el Derecho Internacional del Trabajo y el Derecho Internacional de los Derechos Humanos" (p. 116). Esto debido a que el trabajo se constituye en un derecho inseparable y, por lo tanto, inherente a la dignidad humana, pues a través de él se da la realización de otros derechos humanos (Comisión Nacional de los Derechos Humanos, 2016).

\section{El Fondo Rotatorio de la Policía Nacional y su proceso de desvinculación de personal para el año 2019}

Esta entidad estatal tiene su origen en el Decreto 2361 de 1954 y una de sus funciones es la de confección de uniformes, la cual, de acuerdo al artículo 8 del Decreto 2125 de 2008, se encuentra a cargo de la subdirección operativa de la entidad. Así, para el cumplimiento de esta función cuenta con la Fábrica de Confecciones, adscrita a la subdirección operativa y encargada de los procesos productivos del Fondo Rotatorio de la Policía Nacional, el cual, para el funcionamiento de la fábrica, vinculaba personal a través de la figura de "supernumerarios" que, en su gran mayoría, eran mujeres.

Ahora bien, teniendo en cuenta que la vinculación de supernumerarios, de acuerdo a lo estipulado por el artículo 83 del Decreto 1042 de 1978, se constituye en una modalidad excepcional de vinculación de personal a las entidades del Estado, el Fondo Rotatorio de la Policía Nacional efectuaba estas vinculaciones a través de actos administrativos durante periodos de 3 a 6 meses, pero muchas 
de las mujeres eran vinculadas de manera permanente, llegando algunas de ellas a estar vinculadas a la entidad durante más de 12 años a través de la modalidad de supernumerarias. Además, anualmente no se efectuaba vinculación alguna en el mes de enero, destinando este mes para que las trabajadoras realizaran las gestiones de entrega de documentos y se hicieran practicar exámenes médicos, retomando su vinculación en el mes de febrero.

Así, para el mes de enero de 2019 se convocó a las trabajadoras a efectuar el mismo proceso que habían adelantado en años anteriores, pero en esta oportunidad el Fondo Rotatorio de la Policía Nacional decidió vincular a un número ostensiblemente inferior al del año anterior aduciendo falta de presupuesto, desvinculando así a un grupo considerable de personas que venían trabajando de manera permanente con la entidad, dentro de quienes se encontraban aproximadamente 60 mujeres con discapacidad, sin que, frente a ellas, contara con la autorización del Ministerio del Trabajo, tal y como lo dispone el artículo 26 de la Ley 361 de 1997.

\subsection{Mujeres con discapacidad desvinculadas}

La gran mayoría del personal vinculado para trabajar en la fábrica de confecciones debía operar diversos tipos de máquinas de coser durante turnos de 8 horas, en los cuales debían adelantar acciones repetitivas y someter sus extremidades, muchas veces, a las vibraciones provenientes de estas máquinas; además, debían cumplir con la elaboración de determinadas piezas de uniformes militares, tarea que era evaluada cada hora imponiendo un numero determinado y calificando con un porcentaje el cumplimiento de dicha tarea. En atención a las particularidades en que desempeñaban sus labores, muchas mujeres empezaron a sufrir dolores en sus extremidades superiores, lo que las obligó a acudir a una valoración médica ante las entidades promotoras de salud y la administradora de riesgos laborales a las cuales se encontraban afiliadas; como resultado de estas valoraciones, se determinó que sufrían de diversas patologías ${ }^{(5)}$ de origen laboral, adquiridas durante su vinculación con el Fondo Rotatorio de la Policía Nacional.

Estas patologías fueron puestas en conocimiento del empleador, así como las recomendaciones emitidas por la administradora de riesgos laborales, las cuales ponían de presente algunas restricciones que tenían las mujeres para el desempeño de las labores en la fábrica de confecciones, pese a lo cual, este grupo de personas continuaron desempeñando sus labores y cumpliendo, en su gran mayoría, con las metas que se les asignaba dentro de sus respectivos turnos y actividades. Así, la condición de discapacidad de estas mujeres se predica del

(5) Dentro de las enfermedades de origen laboral diagnosticadas se encuentran el síndrome de túnel carpiano, síndrome de abducción dolora de hombro, bursitis de hombro, epicondilitis bilateral, tenosinovitis de estiloides radial (de quervain) bilateral, síndrome de manguito rotador, tenosinovitis de flexoestensores de carpo bilateral, entre otras. 
padecimiento de una enfermedad laboral, la cual impide que desempeñen la labor de operarias de máquina -a la cual han dedicado buena parte de su vida como fuente de sustento para ellas y sus familias- en igualdad de condiciones con las demás operarias que no padecen una patología de la misma naturaleza; esto teniendo en cuenta que el artículo 2 de la Ley Estatutaria 1618 de 2013 define a las personas con discapacidad como aquellas que "tengan deficiencias físicas... a mediano y largo plazo que al interactuar con diversas barreras incluyendo las actitudinales, puedan impedir su participación plena y efectiva en la sociedad, en igualdad de condiciones con las demás".

\section{Protección del derecho fundamental a la estabilidad laboral reforzada a través de la acción de tutela}

Al tratarse de un derecho fundamental, la estabilidad laboral reforzada puede ser objeto de amparo a través del ejercicio de la acción de tutela, aun cuando este recurso constitucional es de carácter subsidiario y no principal frente a la pretensión del reintegro laboral, pero esta particularidad del recurso se invierte cuando el juez constitucional verifica que en el caso sometido a su conocimiento se materializó el despido de una persona en situación de vulnerabilidad manifiesta sin que existiera autorización expresa del Ministerio del Trabajo o de una instancia judicial, pues en este tipo de casos "no existe dentro de los procesos ordinarios un mecanismo preferente y sumario para que opere el restablecimiento de sus derechos como trabajadores" (Corte Constitucional, 2011:20). Esto debido a que los mecanismos disponibles en las normas procesales laborales no obedecen a la urgencia e irremediabilidad del perjuicio que se puede derivar del desempleo de una persona con discapacidad (Corte Constitucional, 2013).

Así las cosas, las mujeres con discapacidad desvinculadas del Fondo Rotatorio de la Policía Nacional optaron por la interposición de una acción de tutela en contra de esta entidad estatal en procura de que sus derechos fundamentales fueran amparados por los jueces constitucionales. Acción que encontraba su sustento en la postura que al respecto ha mantenido el Alto Tribunal, pues este "en innumerables ocasiones, ha protegido la estabilidad laboral a quienes se les finaliza la relación laboral cuando se encuentran incapacitadas por padecer una enfermedad de origen común o profesional" (Corte Constitucional, 2010:14).

Aunado a lo anterior, pese a la postura de la entidad estatal, según la cual la desvinculación obedecía a la terminación del periodo para el cual habían sido vinculadas, lo cierto es que las particularidades de la figura de supernumerarios, como modalidad de vinculación laboral a la administración, se había desnaturalizado, pues estas mujeres llevaban años trabajando en la fábrica de confecciones del Fondo Rotatorio de la Policía Nacional, situación frente a la cual la Corte Constitucional (2016b) tuvo la oportunidad de pronunciarse en los siguientes términos: 
... la relación laboral que celebra la administración con las personas que vincula como supernumerarios, reviste un carácter eminentemente temporal. En caso de que dicho elemento no esté presente, es decir, si la realidad demostrable apunta a que la relación establecida entre el servidor supernumerario y la administración no es transitoria sino permanente, podrá la autoridad judicial, en este caso, el juez constitucional, derivar las consecuencias que emanan de este hecho, aplicando el principio de primacía de la realidad sobre las formalidades establecidas por los sujetos de las relaciones laborales, principio de rango constitucional. (p. 19)

En adición, jurisprudencialmente se ha establecido que el procedimiento descrito por la Ley 361 de 1997 para el despido de un trabajador con discapacidad debe ser adelantado por todo empleador, por lo que de no contar con la autorización del Ministerio del Trabajo el despido se torna ineficaz, regla que, en aplicación del principio de igualdad, se predica de todos los trabajadores que tengan alguna discapacidad, incluyendo aquellos que padecen una enfermedad común o profesional, sin que sea relevante el tipo de vinculación que exista con el empleador (Corte Constitucional, 2009). Otra de las consecuencias derivadas de la falta de autorización del Ministerio del Trabajo para el despido de una persona con discapacidad es que opera una presunción, consistente en que la terminación del contrato de trabajo se produjo como consecuencia de la discapacidad del individuo, presunción necesaria debido a que el exigir que la persona con discapacidad demuestre esto se constituye en una carga desproporcionada (Corte Constitucional, 2007).

Al respecto, la Corte Constitucional (2016b) ha determinado que esta presunción también aplica en aquellos casos en los que una entidad estatal disponga permanencia de nombramientos de supernumerarios que tengan una discapacidad y con posterioridad proceda a desvincularlo. Presunción que encuentra sustento en el hecho de que "resulta más apropiado desde el punto de vista constitucional, imponer alempleador la carga de probar que el despido tiene como fundamento razones distintas a la discriminación basada en la discapacidad" (Corte Constitucional, 2007).

\subsection{Efectividad de la acción de tutela en el caso objeto de estudio}

Como se enunció con antelación, solamente diez de las mujeres con discapacidad desvinculadas del Fondo Rotatorio de la Policía Nacional optaron por compartir los fallos de las acciones de tutela instauradas en procura de obtener su reintegro a esta entidad aduciendo la vulneración de su derecho fundamental a la estabilidad laboral reforzada. En este sentido, salta a la vista la falta de efectividad del recurso constitucional, pues de las diez acciones de tutela ${ }^{(6)}$ instauradas

(6) Las acciones de tutela fueron conocidas por jueces de distintas especialidades, esto en atención a que según dispuesto por los artículos 37 del Decreto 2591 de 1991 y $1^{\circ}$ del Decreto 1382 de 2000 
solamente tres fueron falladas favorablemente en primera instancia, llegando a ser solamente un caso el fallado a favor ${ }^{(7)}$ dado que en respuesta a los recursos de apelación instaurados en contra de la decisión inicial, tanto por parte de las mujeres con discapacidad como de la entidad accionada, los falladores de segunda instancia decidieron confirmar siete de las decisiones que negaban el amparo constitucional y revocar dos de las decisiones que sí otorgaban tal amparo.

Llama la atención que muchos de los argumentos esgrimidos por los operadores judiciales, en primera y segunda instancia, hacen alusión a aspectos ya resueltos por la jurisprudencia constitucional, motivo por el cual no deberían, en principio, ser utilizados para negar el amparo solicitado por las accionantes. Los más frecuentes son aquellos relacionados con la subsidiaridad de la acción de tutela y la existencia de recursos ordinarios para solucionar la controversia existente entre las mujeres desvinculadas y la entidad accionada; otros, por su parte, se referían a la terminación del periodo para el cual fueron vinculadas las mujeres y la naturaleza eminentemente transitoria de su vínculo con la administración, sin estudiar sus nombramientos previos y el tiempo que llevaban vinculadas a la entidad bajo la figura de supernumerarias, es decir, no se hizo análisis alguno del principio de supremacía de la realidad a pesar de que los periodos consecutivos de vinculación de este grupo de mujeres fue un hecho aceptado por el Fondo Rotatorio de la Policía Nacional en sus respuestas a las acciones de tutela que se instauraron en su contra.

Además, pese a las limitaciones con que contaban las mujeres para el desempeño de determinadas actividades, es posible observar que en muchas de las decisiones se cuestiona la discapacidad de las mujeres, aduciendo que, al poder continuar con sus labores, no se podía predicar la existencia de una discapacidad. Frente a este aspecto, existe un pronunciamiento que exige que la persona tenga una pérdida de la capacidad laboral por lo menos del $15 \%$ para

\footnotetext{
cualquier juez puede conocer de la acción de tutela. En este sentido, los jueces que conocieron en primera instancia estos recursos constitucionales fueron los siguientes: i) Juzgado 28 Laboral del Circuito de Bogotá, rad. 2019-00148; ii) Juzgado 34 Laboral del Circuito de Bogotá, rad. 2019-00128; iii) Juzgado 23 Civil del Circuito de Bogotá, rad. 11001-31-10-026-2019-00108-01; iv) Juzgado 26 de Familia de Bogotá, rad. 2019-00108; v) Juzgado 10 de Familia de Bogotá, rad. 11001-31-10-010-20190023600; vi) Juzgado 12 Civil del Circuito de Bogotá, rad. 2019-0122; vii) Juzgado 22 Laboral del Circuito de Bogotá, rad. 11001310502220190013100; viii) Juzgado 22 de Familia de Bogotá, rad. 11001-31-10022-2019-00176-00; ix) Juzgado 30 Civil del Circuito de Bogotá, rad. 1100131030-30-2019-0089-00; x) Juzgado 43 Civil del Circuito de Bogotá, rad. 11001310304320190009400.

(7) En el presente caso, el fallador de segunda instancia (Sala Civil de Decisión Especializada en Restitución de Tierras Tribunal Superior del Distrito Judicial de Bogotá, rad. 110013103043201900094 01) revocó dos apartes de la decisión inicial, favoreciendo a la mujer con discapacidad, pues determinó que la Entidad accionada debía pagar la sanción de 180 días de salario en favor de la accionante en cumplimiento de lo dispuesto por el artículo 26 de la Ley 361 de 1997 y, además, aclaró que había necesidad de acudir a la jurisdicción de lo contencioso administrativo debido a que se mantenía indemne la presunción del despido por causa del estado de salud de la accionante, por lo que el amparo constitucional no podía ser transitorio (de 4 meses como lo había dispuesto el juez de primera instancia), sino permanente.
} 
que pueda considerarse como una persona con discapacidad titular del derecho a la estabilidad laboral reforzada, postura que el fallador de instancia tomó de dos sentencias de la Sala Laboral de la Corte Suprema de Justicia (rad. SL14134-2015 y SL10538-2016). No obstante, lo anterior, el juez constitucional que tomó como referencia estos pronunciamientos se limitó a transcribir la postura adoptada por ese Alto Tribunal, sin que se surtiera un análisis a fondo de los argumentos que sustentaban el sentido de los fallos, pues de haberlo hecho se habría verificado que la norma en la que soportaron las decisiones se encontraba derogada desde el año 2013 y, por lo tanto, no era procedente su aplicación; además, la norma hacía referencia a una calificación del grado de severidad de la limitación de la persona, pero no hacía alusión concreta al porcentaje desde el cual se podía considerar que una persona tenía una discapacidad.

Por último, algunos de los jueces determinaron que no era procedente la protección constitucional debido a que no se lograba demostrar que existiera un riesgo inminente, urgente e irreparable, pues se trataba de mujeres que, si bien tenían una enfermedad de origen laboral, podían continuar desempeñando algunas actividades, lo que implicaba que estaban en la capacidad de trabajar en otros lugares; sin embargo, no se tuvo en cuenta que se trataba de un grupo de mujeres vulnerables frente a quienes, en aplicación del principio constitucional de solidaridad, los particulares y, en especial, el Estado, en el marco de las relaciones laborales, deben brindar su apoyo en "aquellas situaciones en las que la desigualdad material, la debilidad física o mental, o la falta de oportunidades, les imponen [a las personas] obstáculos mayores en la consecución de sus metas" (Corte Constitucional, 2014:13-14).

Actualmente, de las mujeres con discapacidad desvinculadas por el Fondo Rotatorio de la Policía Nacional solamente se encuentran trabajando aquellas que obtuvieron un fallo favorable en las acciones de tutela instauradas, las demás se encuentran desempleadas debido a que el mercado laboral las rechaza con motivo de su edad y al hecho de padecer una enfermedad laboral que limita las actividades que pueden efectuar, es decir, se materializó el riesgo por ellas alegado, dado que sus derechos al trabajo digno, a la seguridad social, a la estabilidad en el empleo y a la vida digna fueron efectivamente vulnerados por la desvinculación de la cual fueron objeto, vulneración que se mantiene a causa de los fallos que negaron la tutela de sus derechos.

\section{Conclusiones}

El derecho internacional ha surtido una importante evolución en el reconocimiento, protección y garantía de los derechos de grupos que históricamente han sido objeto de discriminación y olvido, tanto por el Estado como por la sociedad, siendo uno de estos grupos el de las personas con discapacidad, frente al cual existen diversos tratados internacionales, jurisprudencia de tribunales regionales 
de derechos humanos y doctrina especializada que, además de delimitar el alcance y contenido de las prerrogativas en favor de aquellas, permite identificar quiénes pueden ser considerados como personas con discapacidad.

Sin embargo, al analizar las decisiones de los jueces constitucionales que fallaron las acciones de tutela que hacen parte del presente estudio se evidencia la falta de conocimiento de algunos de ellos sobre la materia, pues condicionan la situación de discapacidad del individuo a la existencia de una pérdida considerable de la capacidad laboral, aspecto totalmente ajeno a la naturaleza misma de la discapacidad, dado que esta se caracteriza por limitar a la persona en el normal desarrollo de todas las actividades derivadas de la vida en sociedad. En el caso analizado, es clara la existencia de la discapacidad, debido a que las limitaciones ocasionadas por las enfermedades de origen laboral que padecen este grupo de mujeres trascienden las actividades propias de su oficio, ya que, al afectar sus miembros superiores, inciden a su vez en el normal desarrollo de actividades cotidianas.

Con relación a la acción de tutela para la protección del derecho fundamental a la estabilidad laboral reforzada de las personas con discapacidad no puede afirmarse que carezca de efectividad en sentido estricto, esto teniendo en cuenta que existen casos que han sido fallados favorablemente, es decir, este recurso constitucional es, en principio, eficaz porque puede producir el resultado para el cual fue creado (Corte Interamericana de Derechos Humanos, 1988); sin embargo, es evidente que los jueces que conocen de las acciones de tutela optan por inaplicar el precedente constitucional aduciendo la falta de cumplimiento de requisitos por parte del accionante o, incluso, por una interpretación parcializada del precedente. Además, es claro que no se realizó un ejercicio juicioso de interpretación sistemática de la normatividad -nacional e internacional- aplicable, la jurisprudencia constitucional, los hechos y pruebas suministrados por las accionantes, así como del contexto socioeconómico en el cual se presentaron estos casos.

Así, al estudiar los fallos que resolvieron estas acciones constitucionales queda la sensación de que los mismos son resultado de un trámite apresurado, lo que podría explicarse debido a la congestión que caracteriza el sistema judicial colombiano, pero que en ningún momento justifica que se vean comprometidos los derechos fundamentales de un grupo vulnerable y de especial protección constitucional, como lo es el de las mujeres con discapacidad.

\section{Bibliografía}

AVENDAÑO, G. (2014). El derecho laboral como derecho humano. Verba luris, 32, 53-72. Recuperado de http://www.unilibre.edu.co/verbaiuris/32/el-derecholaboral-como\%20derecho-humano.pdf 
CANESSA, M. (2012). Los derechos humanos laborales en el derecho internacional. Revista Latinoamericana de Derechos Humanos, 23 (1), 115-144.

CARRERA, L. (2011). La acción de tutela en Colombia. Revista del Instituto de Ciencias Jurídicas de Puebla, 5 (27), 72-94.

COMISIÓN NACIONAL DE LOS DERECHOS HUMANOS. (2016). Derecho Humano al trabajo y derechos humanos en el trabajo. Ciudad de México: CNDH.

CORTE CONSTITUCIONAL. (1994). Sentencia C-023 del 27 de enero de 1994. Magistrado sustanciador: Vladimiro Naranjo Mesa.

CORTE CONSTITUCIONAL. (1997a). Sentencia T-116 del 01 de abril de 1997. Magistrado Ponente: Jose Gregorio Hernández Galindo.

CORTE CONSTITUCIONAL. (1997b). Sentencia C-470 del 25 de septiembre de 1997. Magistrado Ponente: Alejandro Martínez Caballero.

CORTE CONSTITUCIONAL. (2003). Sentencia C-034 del 28 de enero de 2003. Magistrado Ponente: Eduardo Montealegre Lynett.

CORTE CONSTITUCIONAL. (2007). Sentencia T-1083 del 13 de diciembre de 2007. Magistrado Ponente: Humberto Antonio Sierra Porto.

CORTE CONSTITUCIONAL. (2008). Sentencia T-1210 del 05 diciembre de 2008. Magistrada Ponente: Clara Inés Vargas Hernández.

CORTE CONSTITUCIONAL. (2009). Sentencia T-687 del 01 octubre de 2009. Magistrado Ponente: Humberto Antonio Sierra Porto.

CORTE CONSTITUCIONAL. (2010). Sentencia T-490 del 16 junio de 2010. Magistrado Ponente: Jorge Ignacio Pretelt Chaljub.

CORTE CONSTITUCIONAL. (2011). Sentencia T-864 del 15 noviembre de 2011. Magistrado Ponente: Juan Carlos Henao Pérez.

CORTE CONSTITUCIONAL. (2013). Sentencia T-116 del 07 de marzo de 2013. Magistrado Ponente: Alexei Julio Estrada.

CORTE CONSTITUCIONAL. (2014). Sentencia T-217 del 01 de abril de 2014. Magistrada Ponente: María Victoria Calle Correa.

CORTE CONSTITUCIONAL. (2015). Sentencia T-765 del 16 diciembre de 2015. Magistrado Ponente: Gabriel Eduardo Mendoza Martelo.

CORTE CONSTITUCIONAL. (2016a). Sentencia T-029 del 05 de febrero de 2016. Magistrado Ponente: Alberto Rojas Ríos. 
CORTE CONSTITUCIONAL. (2016b). Sentencia T-683 del 02 de diciembre de 2016. Magistrado Ponente: Gabriel Eduardo Mendoza Martelo.

CORTE CONSTITUCIONAL. (2017a). Sentencia SU-049 del 02 de febrero de 2017. Magistrada Ponente: María Victoria Calle Correa.

CORTE CONSTITUCIONAL. (2017b). Sentencia T-317 del 12 de mayo de 2017. Magistrada Ponente: Antonio José Lizarazo Ocampo.

CORTE CONSTITUCIONAL. (2017c). Sentencia T-433 del 13 de julio de 2017. Magistrado Sustanciador (e): Iván Humberto Escrucería Mayolo.

CORTE CONSTITUCIONAL. (2018). Sentencia SU-040 del 10 de mayo de 2018. Magistrada Ponente: Cristina Pardo Schlesinger.

CORTE INTERAMERICANA DE DERECHOS HUMANOS. (1988). Caso Velásquez Rodríguez Vs. Honduras. Fondo. Sentencia de 29 de julio de 1988. Serie C No. 4.

Decreto 2361 de 1954, publicado en el Diario Oficial No. 28.553 del 18 de agosto de 1954.

Decreto 1042 de 1978, publicado en el Diario Oficial No. 35.035 del 06 de julio de 1978.

Decreto 2591 de 1991, publicado en el Diario Oficial No. 40.165 del 19 de noviembre de 1991.

Decreto 1382 de 2000, publicado en el Diario Oficial No. 44.082 del 14 de julio de 2000.

Decreto 2125 de 2008, publicado en el Diario Oficial No. 47.022 del 16 de junio de 2008.

GUERRERO, G. (1999). Principios Fundamentales del derecho al trabajo. Santa Fe de Bogotá: Leyer.

Ley 361 de 1997, publicada en el Diario Oficial No. 42.978 del 11 de febrero de 1997.

Ley Estatutaria 1618 de 2013, publicada en el Diario Oficial No. 48.717 del 27 de febrero de 2013.

MOLINA, A. (2007). Aproximaciones sobre el derecho al trabajo desde la perspectiva de los derechos humanos. Estud. Socio-Juríd, 9, 166-189.

VÁSQUEZ, A. (1999). Derecho del trabajo y la seguridad social. 8ª ed. Buenos Aires: Astrea. 